Article

\title{
Fraud, Economic versus Social-Psychological Losses, and Sustainable E-Auction
}

\author{
Xiaobing Zhang ${ }^{1}$, Fu-Sheng Tsai ${ }^{2,3, *} \mathbb{B}$, Chih-Chen Lin ${ }^{3}$, Ya-Fang Cheng ${ }^{2}$ and Kun-Hwa Lu ${ }^{2,4}$ \\ 1 Business School, Huaiyin Institute of Technology, Huaian 223001, China; zhangxiaobin49@hotmail.com \\ 2 Department of Business Administration, Cheng Shiu University, Kaohsiung 833, Taiwan; \\ 0359@gcloud.csu.edu.tw (Y.-F.C.); lukunhwa1@hotmail.com (K.-H.L.) \\ 3 Postgraduate Program in Management, I-Shou University, Kaohsiung 840, Taiwan; lincc@tongkang.com \\ 4 Nan Jehn Gas Co. Ltd., Kaohsiung 833, Taiwan \\ * Correspondence: fusheng_tsai@hotmail.com; Tel.: +886-7-731-0606
}

Received: 3 August 2018; Accepted: 28 August 2018; Published: 3 September 2018

check for updates

\begin{abstract}
As compared to the economic losses, social and psychological losses are of equal importance in discussing the losses when encountering fraud. Taking advantage of a perspective paper form (i.e., free writing style with a mix of description, analysis, and comments) with in-depth discussions and well-developed propositions, we combine considerations from the knowledge gap, platform quality, and risk management to discuss the comparative seriousness of different fraud-caused losses. The conceptual model mainly articulates on a series of relationships among different degrees of knowledge gap, platform quality, and risk management in predicting the various combinative losses in the economic, social, and psychological aspects. Propositions follow. First, when the knowledge gap is higher, the economic losses of being cheated on the internet will be higher, while lower in social and psychological losses. Second, when perceived platform quality is higher, the economic losses of being cheated on the internet will be lower, while higher in social and psychological losses. Third, when platform risk management is better, all aspects of being cheated on the internet will be lower. Based on the assumption of network externality, we also argue that the multiple dimensions of fraud-caused losses may damage e-auction sustainability. Theoretical and practical implications will be discussed.
\end{abstract}

Keywords: economic vs. social-psychological losses; internet fraud; e-auction; knowledge gap; platform quality; risk management

\section{Introduction}

In this age of the information explosion and revolution, utilizing the internet to make transactions have already become a daily routine. E-commerce has changed the traditional economic and business models [1]. However, huge profit and business opportunities have also attracted illegal activities such as internet fraud, making e-commerce security a serious concern. A simple instance of such fraud activities is when the customer cannot receive physical products/services after their payments. More seriously, internet fraud activities have become more organized.

Despite the constant development of anti-fraud techniques, an increasing number of internet users are still cheated. As compared to the economic rationale, few studies have studied the reason how people react to fraud from social and psychological perspectives. Nonetheless, social and psychological factors are also key determinants of customer loyalty and satisfaction in e-auction websites [2]. For instance, a reputation based mechanism is increasingly necessary for consumers who may rely on such a method to maintain trust in their business counterparts and the intermediate 
platform in e-auction context [3,4]. Hence, the discussion of social-psychological losses in comparison with economic counterparts is very critical.

To our knowledge, extant studies have either discussed economic, social, or psychological losses alone, or they have largely focused on economic ones. So far, fewer have contributed to an integrative discussion of the influences of an antecedent (e.g., the knowledge gap proposed here) on economic and social-psychological losses in a comparative manner. Thus, the objective of this conceptual piece is to offer an integrative discussion of those distinctive but highly related issues to form a systematic understanding of the interdependence of the three major antecedent factors on the economic versus socio-psychological losses from e-auction fraud.

The present study investigates the abovementioned issue from an integration of three perspectives: website characteristics, knowledge gap between cheater and cheated, and risk management. We argue that, to offer an integrative view, a framework that incorporates website attributes, knowledge gap, and risk management is necessary for a discussion of economic versus non-economic losses. The reasons could reside in the interrelationships among the three important factors in causing potential losses in e-commerce contexts. First, the popularity and convenience of the internet has increased the participation of consumers in internet shopping. However, in many websites, the characteristics of the websites perceived by consumers will affect consumers' perception of the website and even the consumers' Internet consumption behavior. The perceived website characteristics, which includes "site security", "web reliability", "internet shopping convenience" demonstrate consumers' personal awareness of the site. Website characteristics influence and are influenced by the other factors proposed here. For example, Lu and colleagues [5] proposed that trustworthiness leads to consumers' higher evaluation of an e-auction site's friendliness, functionality and interactivity. Secondly, the knowledge gap should be considered. Fundamentally, internet fraud has an ontology of dyads of persons whose interaction is constructed on a basis of cheating and cheated behaviors. In such a premise, studies should know more about the phenomenon of internet fraud from an interactive viewpoint- - that is, analyzing both sides of a dyad of persons. Meanwhile, internet-relevant knowledge has become the source of value and advantages for an individual in the knowledge economy. Past studies have largely focused on exploring either the knowledge possessed by fraudsters or of internet users being cheated during e-commerce. However, research results were often inconsistent, and even contrary to the effect that knowledge level can bring to users. For example, it has been reported that there is still a high proportion of highly educated people who have a high level of knowledge about the internet but are still being cheated by fraudsters. This shows the importance of studying knowledge issues in the context of internet fraud from a relative knowledge gap perspective. In the past, studies on the knowledge gap/distance (or heterogeneity if adopting a triad or group level of analysis) focused more on intraorganizational entity in the physical world. Yet, such an imperative has not been researched a lot in the context of the cyber world. Thirdly, the internet has revolutionized the way individuals and businesses freely share information. Individuals have gained the ability to purchase and sell goods and services online on the internet while online stores have become ultra-convenient, accessible, and most of all, speedy from a variety of devices and reputable online retailers, including EBay, Alibaba and Amazon [6]. According to Mpinganjira [6], the internet has made it possible for these online stores to conduct their commercial transactions electronically, a phenomenon that is widely known worldwide as e-commerce. However, there have been a lot of risks for the managers of online stores associated with management that have resulted in economic and non-economic losses. To managers, the risk has been to manage the problems that result from e-commerce fraud. For instance, Gregg and Scott [7] state that in an auction website such as the popular EBay, the risk to the managers is that the online shoppers may be overcharged by sellers to cause economic losses. This may lead to them leaving the auction website, and thus, lead to a reduction in profits.

Therefore, the website characteristics, knowledge gap between cheater and cheated, and risk management are vital factors that show how economic losses in the context of e-commerce occur. 
As such, the discussion will focus on these factors in addition to e-commerce auction as another factor and their sustainability. Such discussion could generate impact on the relevant literature in the following ways. First, a systematic articulation for the non-economic losses in the context of internet fraud could call for more comprehensive consideration when researching fraud losses. Second, the integration of the three perspectives offers a good reference when researching on the comparative seriousness of different losses cause by fraud. Third, our conceptual framework could stimulate empirical studies in related imperatives discussed here.

\section{Literature Review and Proposition Development}

\subsection{Internet Auction Websites}

We define e-auction sustainability as a persistently good state of maintaining an e-auction business relationship between buyers and sellers. An auction website refers to a shared online space where buyers and sellers go through traditional physical-space bidding procedures with the support of web technology [8]. The main function of the auction website platform is to provide information about the seller and their goods sold to the bidder offering a heist incentive [9]. An online auction has the advantage of convenience [10], time-saving [11], higher diversity in product and services, and unlimited to weather and other physical environmental conditions [12], etc.

It is widely welcomed by consumers, thus grows faster than the traditional auction market [13]. Due to this, Beam, and Segev [14] claimed that a good and standard online auction environment must contain features, including product images, detailed text descriptions, price comparison mechanisms, clear norm, and guidance for transactions. It is such features that Klein and O'Keefe (1999) [13] pointed out that the internet platform as an auction medium is easier to use to start because of low entry barriers, low construction costs, low distribution cost, and synchronized transactional information.

While these auction websites, also known as e-auction platforms are easy to start, they need to be aligned to key business processes and stakeholders [15]. One of these key business processes is value proposition. Value proposition based on precise understanding of consumer needs is critical for an e-auction website's profitability [15]. Tu and colleagues [2] found that the ease of use as website design quality is a value proposition that is essential to customer loyalty and satisfaction in commercial online auctioning services. However, often, the consumer costs or lossesare due to private or idiosyncratic information/knowledge, which legitimizes our concern of the variable of knowledge gaps [16]. Such knowledge like how to use these e-auction websites safely is what create knowledge gaps $[9,13]$.

\subsection{Internet Fraud}

Cybercrime is a new type of crime that is due to the development of information, with different characteristics to traditional forms of crime. In general, internet fraud has the following features: white-collar crime, professional and operational, high degree of losses, high continuity of activities, separation of time and place, technical difficulties in investigation and prosecution, and light penalties.

Internet fraud practices generally include the following: for example, scammers use counterfeit e-mail to defuse the network user's credit card number and other financial information, the use of so-called phishing practices. More representative environments where internet fraud may happen are: online auction platform-cut the standard fraud or false bid; fake network services/false e-commerce shopping sites; real fraud. Since 2004, online games have appeared to be fraudulent in the case of virtual treasure, even more than the amount of fraud that has occurred on online shopping sites. Internet fraud began to appear in online chat rooms in about 2005, asking the victim to send money to the automatic transaction machines (ATM). Criminals also began to use a well-known site in the name of the construction of a pseudo-site, so that consumers in the purchase of selected goods provide personal information, and accidentally fell into the trap; after tracing, it was found that criminals implanted Trojans and other malicious programs. Internet auction merchandise has been the most 
convenient and prosperous channel, yet with hidden crisis and negative impact. In these virtual store transactions, product and information are in separation [17]. That is, buyers need to rely on the auction trading page's texts or picture narrations to know about the product information. This phenomenon makes the buyer over-reliant on the seller's words. Consumers using the virtual store may encounter illegal sellers' fraud: (a) False description: seller text or picture narrative and entity does not match. (b) Illegal bidding, driving up prices: a string of fake buyers participating in the bidding, take the opportunity to drive up prices. (c) Fake sellers drive up prices: fake sellers use the same product fake trading, take the opportunity to drive up the price. (d) Additional fees: trading is not clear, additional charges, such as: freight and so on. (e) The source of the goods is unknown: the source of the goods sold by the illegal seller have a mark that is not clear. (f) Credit card information is stolen [18].

More seriously, because of the nature of e-auctions, including higher anonymity, a huge amount of transactional opportunity, and low entry cost, fraudsters like to build frauds in auction activities [19]. Basically, internet fraud in e-auction happens when the winner(s) of the auction do not receive what s/he should expect to receive [20].

\subsection{Social-Psychological Losses from Internet Fraud}

In addition to economic losses from internet fraud, there should be serious concern about the social and psychological losses. Simply and practically, often those being cheated in an e-auction activity are 'winners' of a bidding or auction, but they are eventually 'failed' in fulfilling their expectation of being a winner and even have economic losses. In such a situation, it is inevitable that the social and psychological state of those being cheated is hurt. Methodologically in research of relevant studies, the number of those embarrassed about being cheated who are not willing to be studied might even be underrepresented [20], which provides practical evidence for the non-economic losses. Knowing so, however, there are relatively fewer systematic studies of those being cheated from the social psychological perspectives. Consumer losses can go beyond the financial to the non-monetary level (i.e., social-psychological). The psychological loss of online fraud can be discussed from three aspects: trust, self-esteem and emotion. First, the impact of fraud on trust. Luhmann [21] mentions that trust is a way to solve specific risk problems, and trust must be obtained from the familiar world, and the promotion of trust becomes the key to the success of buyers and sellers one. Ganesan [22] suggests that the two facets of trust are "reliable" and "benevolent". In a risky situation, the trustee will rely on the experience of the trustee in the past, or in the absence of any interactive experience. The information provided by the third party and the information obtained in the initial interactive experience generate trust. The behavior of online transactions may give consumers the risk of uncertainty, so consumers fear that the mentality of fraud has affected a considerable degree of trust. Mayer et al. [23] also believe that trust can occur at a high degree of risk, uncertainty, and lack of understanding or incomplete information on both sides of the transaction. Trust is of special importance of consumer satisfaction in online auctions [2]. Consumers will be afraid of the fact that internet trading behavior is not conducive to their own losses or damage.

Second, the impact of fraud on self-esteem. In the face of internet fraud, those being cheated would often feel a negative self-image, being afraid to talk about the fraud experience publicly, and then suffer from damage to their self-esteem. Thus, most of the victims have low self-worth and high anxiety, and it is therefore easy to experience a sense of isolation, self-depreciation, camouflage intention [24]. If the psychological level of the person who is scolded by the fraudster is not properly relieved or treated, the psychological trauma will produce a psychological imbalance after the fraud.

Thirdly, the impact of fraud on emotional disorder. Ellis [25] argues that emotion is a complex state of human response and perception, and is a state of cognitive-perception. Lazarus [26] also argues that emotion is a complex psychological process and puts forward the emotional theory model of "cognition-motivation-relationship", that emotion is a product of interaction between individual and environment, positive and negative emotions are two sides Events, circumstances, personal assessment and processing results. Many scholars and much research have pointed out that in the case of internet 
fraud, negative emotions in the majority of cases, not a single type of appearance but often several emotions, will "cluster", be "composite" and coexist in other ways.

Proposition 1. Beyond economic losses caused by internet fraud, there may also be social and/or psychological losses in terms of trust, self-esteem, and emotional disorders.

\subsection{Knowledge Gap}

The emergence of new media has changed the cultural characteristics, meaning and influence of the old media $[27,28]$. Compared to the increase in the use of the internet population, other media users are relatively reduced. Different media users are not equal, creating a knowledge gap. Donohue et al. [29] summed up the five factors that led to the knowledge gaps; differences in communication skills: communication skills that produce information asymmetries that lead to the knowledge gap; knowledge storage: differences in time and space where knowledge is stored, as well as storage methods that may cause knowledge gap results; network link: higher socioeconomic class, more relevant and diverse interpersonal network link, resulting in high knowledge gaps; selective reception: the face of multiple information, selective contact, reception and storage that lead to variation in interpretations and thus knowledge gap; media system: the decision of media systems in releasing varieties of information leading to knowledge gap.

Information asymmetry is one that should be minimized to reduce the likelihood of internet fraud [20]. This means that a large gap in knowledge levels of buyer and seller in an e-auction relationship may lead to an environment for the easy implementation of fraud. The level of knowledge of scammers can be measured as computer and internet skills, online system operating experience, fraudulent experience, eloquence, legal knowledge, and fraud organization membership. The victim's knowledge level assessment can be done with: computer and network-related information, understanding of existing fraud practices, online shopping experience, experience of being cheated, information update ability, interpersonal network as information sources.

In the above classification, the probability of being defrauded depends on the degree of knowledge gap. Knowledge economy literature has told us that people with a higher level of knowledge expertise can authorize their profession to obtain higher economic return and profits. Nonetheless, few have formally hypothesized on how the cheated persons would respond to fraud in his/her minds. The knowledge gap becomes extremely vital when the cheater (scammer) and the cheated (victim) meet in an e-commerce platform, such as eBay and Amazon [7]. When the knowledge gap is higher, the scammers and the cheated persons have a large gap in the understanding of the fraud. If the knowledge levels of the scammers and the victims are comparably close, it is not necessarily affected; that is, the probability of fraud is lower. Often, the lower educational level of a victim means that fraud is not fully understood and the operation is not familiar, easily leading to incorrect decisions regarding spending or payment resulting in high monetary (economic) losses [30,31].

Usually, when people possess lower levels of capability or knowledge, their self-consciousness from such social comparison can suppress their expectation of things, including their transactions via the internet. When the knowledge gap is higher, the scammers are knowledgeable but the knowledge level of the cheated is insufficient, the psychological loss of the fraud felt by the cheated persons is lower, and the psychological loss will be lower [32].

However worse, when the cheater has a higher knowledge of scamming people on e-commerce platforms through fraudulent experience of acquiring personal information, such as bank account numbers and the cheated person does not have a higher knowledge of how the cheaters do this, the cheated person is likely to experience significant economic losses in terms of theft of money from their bank account.

Proposition 2. The higher the knowledge gap, comparatively, the higher the economic losses and lower social-psychological losses of users when being cheated. 


\subsection{Perceived Platform Characteristics}

Chung and Young [33] surveyed 602 Korean consumers using an online bookstore to develop a model that suggests that general online shoppers believe that there are five key elements that will affect the commitment to the site platform, respectively: user interface quality: the system design, operation sequence and easy to search for product service information, so that consumers can browse easily; product information quality: the product attributes, real-time product information, adequate production so that consumers can choose and described with the physical goods must be consistent; service information quality: including membership information, problem forum, order and delivery and promotion; security: online payment security and reliability and confidentiality and related user authentication, information and transaction security; website platform reputation: the company's own additional information, such as: corporate image, reputation. Generally, academic studies would consider these following dimensions summarize platform quality.

1. Network security. Freehill, Hollingdale and Page pointed out in a survey in 2000 that most consumers believe that personal internet information cannot be guaranteed, so the development of e-commerce is difficult. The report points out that $18 \%$ of the site platform has the option of providing privacy protection for users, $12 \%$ of the website platform has a statement of its privacy to the user, and only $6 \%$ of the site platform employs external reviewers View the relevant standards for privacy. As the platform operators give less attention to consumers engaged in e-commerce personal data confidential security issues, so consumers reduce their willingness to engage in online shopping.

2. Reliability of the network. The reliability of the network is mainly to explore the trustworthiness of the website characteristics. Turban, King, Lee, Warkentin and Chung [18] pointed out that the average consumer believes that in e-commerce, consumer trust and consumer platform reliability are such that, in a risky situation, an individual who is trading is still willing to be in a position that may be lost by another individual's behavior, and define it as a state of mind of being willingness to engaging individuals to continue to interact to achieve the common goal. When the consumer chooses to trade through the web platform, the problem of information asymmetry [34] is generated when the consumer cannot obtain the quality information of some of the goods, which will cause the transaction to be untrustworthy. Ganesan [22] presents two facets of trust: 1 . credibility (trustworthiness), trading partners can fulfill their commitments and intent to effectively implement the work and the degree of trustworthiness. 2. benevolence, the care of our partners is not only because of the motives of our interests, the goodwill of the heart, and even the willingness to sacrifice their interests. Morgan [35] defines trust as "confidence in the reliability and integrity of trading partners." In a virtual path environment, online shoppers generally believe that trading with electronic retailers must be riskier than the physical world, so consumers must consider whether the commitment of the electronic retailer is reliable (trustworthiness). Thus, trust can be extended to "belief in the ability, reliability and security of the system in high-risk situations" [36].

3. Network convenience. Gillett shows that the consumers believe that the biggest advantage of online shopping at home is convenience, if the order can be delivered safely, and that such delivery can save their time and energy $[37,38]$. Burke [39] points out that online shopping allows consumers to visit stores at any time, reduce transportation and parking problems, and save time waiting for payment. The study also found that convenience is the most often cited as a reason to shop online. Overall, the above characteristics in the minds of consumers can be re-aggregated as an indicator of an overall quality characteristics of a website.

4. There are many attributes of perceived website characteristics, among which the perceived quality and the behavior of website consumption are more closely related to the present article. The perceived quality of the site is defined as the experienced degree of quality that consumers perceive from the overall performance of the site. 
5. The higher the maturity of the website, the higher the perceived quality of the website; instead, the more lacking practical experiences may lead to fraud events and judgement. When consumers perceive the quality of the site to be lower, there is a greater the likelihood of cyber-fraud, and the higher the money loss. When they perceive higher quality of the site, higher maturity, and resulting trust, emotional and self-esteem, there is a greater sense of loss when being cheated and the higher the loss of non-monetary fraud.

6. Cohen and Felson put forward the theory of daily activity, arguing that the following three elements must be aggregated in time and space [40]. Appropriate subject matter, being sufficient to curb the occurrence of a crime is not present; and having the ability and motives of the perpetrators. When the three conditions of polymerization, only the occurrence of criminal acts. Only the above conditions to take control, one can reduce crime. But the network fraud with WWW (World Wide Web) multimedia features has improved the affinity of the use of the network, so that the ability of the scammer to easily find the "right" subject for crime is increased. Only if one can improve the perceived quality and maturity of the site, meanwhile strengthening the user/customer psychological cognition, can the loss of money and non-monetary loss be effectively reduced and high network transaction quality achieved.

Tassabehji [41] noted that perception is a vital dimension for understanding the influences of e-auction platform on the behaviors of users. One of the noteworthy merits of an e-auction platform as Tassabehji put it is to build good relationships between potential users (e.g., building a relationship of user organization to its suppliers). In such view, the characteristics of an e-auction platform may affect the social-psychological state of a user before, during the period, and especially after the fraud has happened. Perception is the external understanding of the human brain to the outside world as a whole. It organizes and explains our sensory information to such an outside environment. In cognitive science, it can also be a set of procedures, including access to sensory information, understanding of information, screening information, organizational information. Different from feeling, perception is reflected by the object of the various attributes and the relationship between the whole.

As a results, perception of an e-auction platform's quality can alter the expectations and responses of a user to the platform, and thus influence the dynamics of losses feeling in social and psychological dimensions. When the perceived quality is higher, it means that the quality of the design, procedures, and other characteristics of an e-auction platform is commonly and positively evaluated. Thus, it is obvious that such a platform would have less chance to cause very serious problem that leads to big economic losses when fraud happens. On the other hand, when the common perception of quality of users are high, they have higher expectation and standard of what the platform should do to prevent internet fraud. When internet frauds somehow do happen, they have greater level of social (e.g., trust) and psychological (e.g., confidence) losses.

Proposition 3. The higher the website quality, comparatively the lower the economic losses and higher social-psychological losses of users when being cheated.

\subsection{Risk Management}

Crisis is a situation in which individuals, groups, or organizations cannot deal with normal procedures because of sudden change [42]. When there is platform crisis, the website will fall into a situation of confusion and anxiety. Different scholars have different opinions in the definition of the crisis. Lerbinger [43] defines a crisis as a matter of a potential threat to the company's future profitability, growth, and even survival. In the author's definition, it has the following characteristics: first, managers must recognize the threat, and believe that this threat will hinder the company to develop the primary goal; second, it must be recognized that if no action is taken, the situation will worsen and be irreversible. Many scholars argue that the crisis has several characteristics that include: the emergence of favorable decisions under crisis, time constraints, the core of the coercive target, and the decision making in time constraints $[44,45]$. 
There are many sources of crisis, and the angle and manner of the cut will be based on the study. Lerbinger classifies the crisis into seven major types: natural crises, technological crises, conflict crises, malicious crises, and management values-distorting crises, deceiving crises, and managing failures. Among them, innovation and technology to promote the human experience may cause more crisis than natural disasters. For example: improper operations in production lines can cause industrial accidents, computer viruses, hackers invasion, theft of information, etc. (that is, a computer application crisis) and will cause great losses.

Boyd [46] states that the perceived platform characteristics that have been discussed, including network security, reliability of network and network convenience are extremely important in determining how the online users of e-commerce auction websites such as EBay and Amazon perceive them. If the websites have a reliable network security, the users are more likely to perceive it is safe to give it its personal information like a bank account number [47]. However, if the opposite is true, the perception of these users will change because they will perceive their money will be stolen by hackers. The effect of this as shown above will be a greater level of losses both in trust and confidence.

Gavish and Tucci [20] found that insurance policy specifically offered for e-auction activities may facilitate consumer willingness to trust in the e-auction. Reading and knowing the insurance policy does not lead the consumers to misunderstand and assume $100 \%$ safety but would help them to be 'prepared' for potential risk. Put differently, an insurance policy not only urges the platform (i.e., the insurance provider) to more actively monitor for and prevent from potential fraud activity (thus can minimize economic losses), it also increases consumers' psychological readiness if fraud is happening.

The seven major types of risk in management that have been mentioned show that operating an e-commerce auction website is not an easy task; rather, it is a difficult one that takes in a lot of considerations. A good example that has been mentioned is the improper operations in production lines. They may include but are not limited to computer viruses, theft of information, and invasion of hackers who have malicious intent such as stealing personal information like bank account numbers [48]. Therefore, a lot of care needs to be taken by the managers who operate e-commerce auction websites such as EBay and Amazon in order to minimize risks associated with online technology.

Proposition 4. When there is better risk management implemented by the website, both the economic and social-psychological losses caused by fraud would be lower.

\subsection{Differentiated Losses and E-Auction Sustainability}

As this paper separates different dimensions of losses caused by fraud in e-auction services, it is argued that the interactive effects of these different losses may affect e-auction sustainability. Specifically, we argue that, as compared to one sort loss situation, multiple losses in different dimension may cause larger, negative development for sustainable e-auction. Gavish and Tucci [20] have noted that fraud in an e-auction business can lead to harmful results with multiple dimensions of consumer consequences due to network externality. When consumers perceived that there is potential danger of being cheated in the process of auction and potential losses are likely, fewer would be willing to continue using the e-auction services, leading to even fewer consumers maintained in the e-auction platform.

It is apparent that sustainability of e-auction websites such as EBay and Amazon depends heavily on the perceptions of consumers in the community. Boyd [46] addresses this issue of the perceptions of consumers in the community. He claims that these websites, especially EBay, depend heavily on the foundation of trust between themselves and their users. If their users feel that there is no trust because of fraudulent behaviors, including the selling of personal information and stealing of people's money through their bank account numbers, their business model becomes extremely unsustainable and, thus, they stand a higher chance of losing a lot of money. Therefore, e-auction websites' focus needs to be on sustainability more than profit. 
Proposition 5. Different dimensions of fraud-caused losses can magnify the effects ofeach other to generate network (dis)externality and damage e-auction sustainability.

\section{Theoretical Implications}

The implications of a knowledge gap are numerous. When the knowledge gap between the cheater (scammer) and the cheated (victim) widens; that is, when the cheater, for example, sells defective products to the cheated, there will be an economic loss [7]. However, beyond the loss of money, the cheated may experience psychological losses such as a lack of trust of the e-commerce auction website.

The implications of perceived platform characteristics, including network security, reliability of the network and network convenience are insightful. When a user is cheated, for example, after the purchase a product from a website that is perceived to be of good quality with a good network and they do not receive it, the user is more likely to suffer economic losses, especially if the product is expensive [46].

The implications of the risks that managers experience when operating an e-commerce auction websites are discerning. When a user on a lowly ranked e-commerce auction website experiences losses in money due to fraud caused by computer viruses or invasion by hackers; that user is less likely to suffer huge economic and social-psychological losses [47].

The implications of not having a sustainable e-commerce auction website are several. Since these websites depend heavily on the foundation of trust between their users and themselves, an activity that is viewed by the user to be inspiring a lack of trust such as stealing of people's money through their bank accounts and selling of personal information may result in a business model that is not sustainable [48].

\section{Practical Suggestions}

Our first argument clarifies that there may be non-economic losses from e-auction fraud. Although such an argument seems to be self-evident, few works of literature have focused on the comparative discussion. Such a discussion urges practitioners of e-auctions (i.e., both the websites and the users) to pay more attention to the potential social-psychological losses caused by fraud. A suggestion for the websites (i.e., the service providers) should be that they are more committed to post-fraud analysis that may gain critical information of the non-economic losses from the cheated customers. For example, a survey may be sent to the cheated users to assess their social-psychological losses, and thus offer possible make-up to retain their trust in the website. For the users, ex ante preparation for preventing a potential fraud event, as well as ex post adjustment for social and/or psychological dissonance, should both be understood and treated as necessary procedures when enjoying e-auction convenience.

More specifically, the three propositions of comparative effects of antecedent factors on different losses may offer suggestions for practices. First, we have argued that the higher the knowledge gap, comparatively there would be higher economic losses and lower social-psychological losses of users when being cheated. It is suggested to both the websites and their users that they continuously level up their technological and managerial knowledge of e-auctions to prevent a gap in knowledge level between them and the fraudsters. Practically, the websites and their users should become the mutual learning counterparts of each other-the websites constantly offer useful knowledge to their users and the users constantly contribute practical feedback to the websites. Second, we have argued that the higher the website quality, comparatively there would be lower economic losses and higher social-psychological losses of users when being cheated. We suggest that both the website and their users may not ignore the possibility of any fraud intention given a high level of quality. Messages and designs for preventing fraud are never "too much"; however, a high level of quality of a website is. Third, we have argued that when there is better risk management implemented by the website, both the economic and social-psychological losses caused by fraud would be lower. Users should support the website to implement good risk prevention solutions even those solutions might charge some fees. 
At least, like the damage insurance options in the cellphone industry as an instance, risk management solutions for fraud may become a service option that websites offer to their users to choose from.

Sustainable e-business is an ultimate goal for nearly every website. Our discussions offered a clear guideline for an e-auction website about what dimensions to invest in pre- and post-auction fraud stages to minimize both economic and non-economic losses. Sustainability can only be realized when a trust is established between a user and an e-commerce auction website. Therefore, a good suggestion will be for the e-commerce auction websites to inspire trust by putting in place measures that strengthen the aforementioned mechanisms of knowledge gap shortening, website quality improvement, and risk management soundness.

\section{Conclusions}

Information technology could bring competitive advantages if utilized well [49]. However, if misused, negative outcomes that may be even beyond the imagination could be harmful to users. Internet-based fraud in e-auction context is an important context to illustrate the aforementioned argument. This perspective article logically discusses the issue of social-psychological losses of internet fraud victims, as well as the antecedents that lead to economic versus social-psychological losses from individual and dyadic levels of analyses. We contribute by arguing that social-psychological losses are as equally important as the economic losses, academically and practically. We also argue that the leading factors to these losses can stand beyond an individual level of analysis, but to a dyadic level, because the nature of the internet fraud behavior is interactive.

Academic implications follow. First, the victims' perceptions of the website can determine the expectation level of the transactions completed via the site. That is, whether the website's objective quality is good or not, the users' perception has a dominant influence on the level of quality standard he sets regarding the transactions he is going to make. Future studies can try to explore other perceptual factors that can affect the setting of quality level (and thus can influence the results in social-psychological losses). Second, we have logically proposed that the gap between the cheater and the victim's dispositional traits, especially those professional ones, such as the knowledge gap we discussed here, can lead to tensions between economic and social-psychological losses. While some factors may lead to low economic losses, others may lead to high social-psychological losses. More research can be conducted into the cheater-cheated distance in other different dimensions (e.g., owned resources, social supports, status, etc.), and what can resolve the tensions between economic and social-psychological losses. Third, research can go further to other levels of analyses, such as the group level or group-against-group level (e.g., a group of cheater committing fraud onto a group of victims), to explore more phenomenological possibilities.

Our discussions lead to the following suggestions of practices. First, internet firms can decrease potential monetary and non-monetary losses for users by simultaneously improving users' website quality perception and strengthening risk management (and even prevention) solutions. Second, internet firms or platforms need to pay attention to the make-up for social-psychological losses, in addition to economic ones. From time to time, the corporate image left to the internet fraud victims can endure longer if the image is formed more by social-psychological memory than monetary loss. From a customer relationship management perspective, the losses due to social-psychological factors may demand more time and effort to recover from.

Author Contributions: X.Z. was the major author for the first draft; F.-S.T. is responsible for the development of propositions and was in charge of completing revision and re-submission; C.-C.L. and Y.-F.C. articulated the Conclusion and Implications.

Funding: The paper was partially sponsored by Business Administration Disciplines of Huaiyin Institute of Technology.

Acknowledgments: This paper is partially supported by the Business Administration Discipline of Huaiyin Institute of Technology.

Conflicts of Interest: The authors declare no conflict of interest. 


\section{References}

1. Mahadevan, M. Business Models for Internet-Based E-Commerce: An Anatomy. Regents Univ. Calif. CMR 2000, 42, 55-69. [CrossRef]

2. Tu, C.-C.; Fang, K.; Lin, C.-Y. Perceived Ease of Use, Trust, and Satisfaction as Determinants of Loyalty in e-Auction Marketplace. J. Comput. 2012, 7, 645-652. [CrossRef]

3. Gregg, D.G.; Scott, J.E. The Role of Reputation Systems in Reducing On-Line Auction Fraud. Int. J. Electron. Commer. 2006, 10, 95-120. [CrossRef]

4. Utz, S.; Matzat, U.; Snijders, C. On-line Reputation Systems: The Effects of Feedback Comments and Reactions on Building and Rebuilding Trust in On-line Auctions. Int. J. Electron. Commer. 2009, 13, 95-118. [CrossRef]

5. Lu, J.; Wang, L.Z.; Yu, C.S.; Wu, J.-Y. E-auction web assessment model in China. Electron. Commer. Res. 2009, 9, 149-172. [CrossRef]

6. Mpinganjira, M. Risk Management, Trust and Repeat Online Shopping Intentions: A South African Perspective; IGI Global: Hershey, PA, USA, 2015. [CrossRef]

7. Gregg, D.G.; Scott, J.E. A Typology of Complaints AboutEbay Sellers. Commun. ACM 2008, 51, 69-74. [CrossRef]

8. Van Heck, E.; Ribbers, P.M. Experiences with Electronic Auctions in the Dutch Flower Industry. Electron. Mark. 1997, 7, 29-34. [CrossRef]

9. Beam, C.; Segev, A. Auctions on the Internet: A Field Study; CMIT Working Paper; 98-WP-1032; Fisher Center for Management and Information Technology, Walter A. Haas School of Business, University of California, Berkeley: Berkeley, CA, USA, 1998.

10. Forsythe, S.M.; Shi, B. Consumer patronage and risk perceptions in Internet shopping. J. Bus. Res. 2003, 56, 867-875. [CrossRef]

11. Mcquitty, S.; Peterson, R.T. Selling home entertainment on the Internet: an overview of a dynamic marketplace. J. Consum. Mark. 2000, 17, 233-248. [CrossRef]

12. Huang, W.Y.; Schrank, H.; Dubinsky, A.J. Effect of brand name on consumers' risk perceptions of online shopping. J. Consum. Behav. 2004, 4, 40-50. [CrossRef]

13. Klein, S.; O'Keefe, M. The Impact of the Web on Auctions: Some Empirical Evidence and Theoretical Considerations. Int. J. Electron. Commer. 1999, 3, 7-20. [CrossRef]

14. Segev, A.; Gebauger, J.; Beam, C. Procurement in the Internet Age-Current Practices and Emerging Trends (Results from a Field Study); CMIT Working Paper; Fisher Center for Management and Information Technology, Walter A. Haas School of Business, University of California, Berkeley: Berkeley, CA, USA, 1998; pp. 7-92.

15. Shin, J.; Park, Y. On the creation and evaluation of e-business model variants: The case of auction. Ind. Mark. Manag. 2009, 38, 324-337. [CrossRef]

16. Krasnokutskaya, E. Identification and Estimation of Auction Models with Unobserved Heterogeneity. Rev. Econ. Stud. 2011, 78, 293-327. [CrossRef]

17. Lee, H.G. Do electronic marketplaces lower the price of goods? Commun. ACM 1998, 41, 73-80. [CrossRef]

18. Turban, E.; King, D.; Lee, J.; Warkentin, M.; Chung, H.M. Electronic Commerce: A Managerial Perspective, 2nd ed.; Prentice Hall: Upper Saddle, NJ, USA, 2002.

19. Noufidali, V.; Thomas, J.S.; Jose, F.A. E-Auction Frauds-A Survey. Int. J. Comput. Appl. 2013, 61, 41-45.

20. Gavish, B.; Tucci, C. Reducing Internet auction fraud. Commun. ACM 2008, 51, 89-97. [CrossRef]

21. Luhmann, N. Trust and Power; John Wiley \& Sons: Hoboken, NJ, USA, 1979.

22. Ganesan, S. Determinants of long-term orientation in buyer-seller relationships. J. Mark. 1994, 58, 1-19. [CrossRef]

23. Mayer, R.C.; Davis, J.H.; Schoorman, F.D. An Integrative Model of Organizational Trust. Acad. Manag. Rev. 1995, 20, 709-734. [CrossRef]

24. Burgard, A.; Schlembach, C. Frames of Fraud: A Qualitative Analysis of the Structure and Process of Victimization on the Internet. Int. J. Cyber Criminol. (IJCC) 2013, 7, 112-124.

25. Ellis, A. Humanistic Psychotherapy; McGraw-Hill: New York, NY, USA, 1979.

26. Lazarus, R.S.; Lazarus, B.N. Passion and Reason: Making Sense of Our Emotions; Oxford University Press: New York, NY, USA, 1994.

27. Meyrowitz, J. Multiple Media Literacies. J. Commun. 1998, 48, 96-108. [CrossRef] 
28. Postman, N.; La, B.R. Critical Thinking in the Electronic Era. Natl. Forum 1985, 65, 4.

29. Donohue, G.A.; Tichenor, P.J.; Oilen, C.N. Mass Media and the Knowledge Gap A Hypothesis Reconsidered. Commun. Res. 1975, 2, 3-23. [CrossRef]

30. Wei, L.; Hindman, D.B. Does the Digital Divide Matter More? Comparing the Effects of New Media and Old Media Use on the Education-Based Knowledge Gap. J. Mass Commun. 2011, 14, 216-235, ISSN 1520-5436. [CrossRef]

31. Kastberg, P. Knowledge Asymmetries-Beyond to Have and Have Not. Fachsprache 2011, XXXIV, 137-151.

32. Russell, G.; George, L. An Information-Gap Theory of Feelings about Uncertainty. 2016. Available online: https:/ / www.cmu.edu/dietrich/sds/docs/golman/Information-Gap\%20Theory\%202016.pdf (accessed on 30 August 2018).

33. Chung, H.P.; Young, G.K. Identifying key factors affecting consumer purchase behavior in an online shopping context. Int. J. Retail. Distrib. Manag. 2003, 31, 16-29.

34. Ba, S.; Pavlou, P.A. Evidence of the Effect of Trust Building Technology in Electronic Markets: Price Premiums and Buyer Behavior. MIS Q. 2002, 26, 243-268. [CrossRef]

35. Hunt, M.; Hunt, J. The Commitment-Trust Theory of Relationship Marketing. J. Mark. 1994, 58, $20-38$.

36. Kini, A.; Choobineh, J. Trust in electronic commerce: definition and theoretical considerations. In Proceedings of the Thirty-First Hawaii International Conference on System Sciences, Kohala Coast, HI, USA, 9 January 1998; Volume 4, pp. 51-61.

37. Gillett, P.L. A profile of urban in-home shoppers. J. Mark. 1970, 34, 40-45. [CrossRef]

38. Darian, J.C. In-home shopping: Are there consumer segments? J. Retail. 1987, 63, 163-186.

39. Burke, R. Do You See What I See? The Future of Virtual Shopping. J. Acad. Mark. Sci. 1997, 5, 352-360. [CrossRef]

40. Cohen, L.; Felosn, M. Social change and crime rate trends: A routine activity approach. Am. Sociol. Rev. 1979, 44, 488-608. [CrossRef]

41. Tassabehji, R. Understanding e-auction use by procurement professionals: motivation, attitudes and perceptions, Supply Chain Management. Int. J. 2010, 15, 425-437.

42. Iyengar, S.; Simon, A. News Coverage of the Gulf Crisis and Public Opinion A Study of Agenda-Setting, Priming, and Framing. Commun. Res. 1993, 20, 365-383. [CrossRef]

43. Lerbinger, O. The Crisis Manager: Facing Risk and Responsibility; Lawrence Erlbaum Associates: Mahwah, NJ, USA, 1997.

44. Barton, L. Crisis in Organizations I; South-Western Publishing Co.: Mason, OH, USA, 1993.

45. Deutsch, K.W. Crisis decision-making: the information approach KW Deutsch. Manag. Int. Crises 1982, 1-22.

46. Boyd, J. In Community We Trust: Online Security Communication at eBay. J. Comput. Mediat. Commun. 2002, 7. [CrossRef]

47. Rustad, M. Private Enforcement of Cybercrime on the Electronic Frontier. South. Calif. Interdiscip. Law J. 2001, 11, 63-116.

48. Nikitkov, A.; Stone, D. Eluding the Lemons: Buyer Mindfulness and Seller Deception in Online Auctions. J. Forensic Investig. Account. 2015, 7, 307-356.

49. Mikalef, P.; Pateli, A. Information technology-enabled dynamic capabilities and their indirect effect on competitive performance: Findings from PLS-SEM and fsQCA. J. Bus. Res. 2017, 70, 1-16. [CrossRef]

(C) 2018 by the authors. Licensee MDPI, Basel, Switzerland. This article is an open access article distributed under the terms and conditions of the Creative Commons Attribution (CC BY) license (http:/ / creativecommons.org/licenses/by/4.0/). 